\title{
Mucoadhesive and Rheological Studies on the Co-Hydrogel Systems of Poly(Ethylene Glycol) Copolymers with Fluoroalkyl and Poly(Acrylic Acid)
}

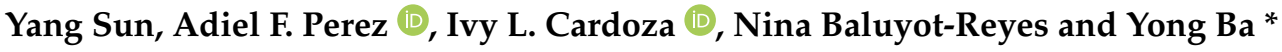 \\ Department of Chemistry and Biochemistry, California State University, Los Angeles, CA 90032, USA; \\ youngsoon1987@gmail.com (Y.S.); apere330@calstatela.edu (A.F.P.); icardoz@calstatela.edu (I.L.C.); \\ nbaluyo@calstatela.edu (N.B.-R.) \\ * Correspondence: yba@calstatela.edu; Tel.: +1-323-343-2360
}

check for updates

Citation: Sun, Y.; Perez, A.F.; Cardoza, I.L.; Baluyot-Reyes, N.; Ba, Y. Mucoadhesive and Rheological Studies on the Co-Hydrogel Systems of Poly(Ethylene Glycol) Copolymers with Fluoroalkyl and Poly(Acrylic Acid). Polymers 2021, 13, 1956. https://doi.org/10.3390/ polym13121956

Academic Editor: Elisabetta Ranucci

Received: 16 April 2021

Accepted: 10 June 2021

Published: 12 June 2021

Publisher's Note: MDPI stays neutral with regard to jurisdictional claims in published maps and institutional affiliations.

Copyright: (c) 2021 by the authors. Licensee MDPI, Basel, Switzerland. This article is an open access article distributed under the terms and conditions of the Creative Commons Attribution (CC BY) license (https:/ / creativecommons.org/licenses/by/ $4.0 /)$.
Abstract: A self-assembled co-hydrogel system with sol-gel two-phase coexistence and mucoadhesive properties was developed based on the combined properties of fluoroalkyl double-ended poly(ethylene glycol) $\left(\mathrm{R}_{\mathrm{f}}-\mathrm{PEG}-\mathrm{R}_{\mathrm{f}}\right)$ and poly(acrylic acid) (PAA), respectively. We have synthesized an $R_{\mathrm{f}}$-PEG-g-PAA (where g denotes grafted) copolymer and integrated it into the $\mathrm{R}_{\mathrm{f}}$-PEG- $\mathrm{R}_{\mathrm{f}}$ physically cross-linked micellar network to form a co-hydrogel system. Tensile strengths between the co-hydrogel surfaces and two different sets of mucosal surfaces were acquired. One mucosal surface was made of porcine stomach mucin Type II, while the other one is a pig small intestine. The experimental results show that the largest maximum detachment stresses (MDSs) were obtained when the $\mathrm{R}_{\mathrm{f}}$-PEG-g-PAA's weight percent in the dehydrated polymer mixture is $\sim 15 \%$. Tensile experiments also found that MDSs are greater in acidic conditions $(\mathrm{pH}=4-5)\left(123.3 \mathrm{~g} / \mathrm{cm}^{2}\right.$ for the artificial mucus, and $43.0 \mathrm{~g} / \mathrm{cm}^{2}$ for pig small intestine) and basic conditions $(\mathrm{pH}=10.6)\left(126.9 \mathrm{~g} / \mathrm{cm}^{2}\right.$, and $44.6 \mathrm{~g} . \mathrm{cm}^{2}$, respectively) than in neutral $\mathrm{pH}\left(45.4 \mathrm{~g} / \mathrm{cm}^{2}\right.$, and $30.7 \mathrm{~g} . \mathrm{cm}^{2}$, respectively). Results of the rheological analyses using shear strain amplitude sweep and frequency sweep reveal that the $\mathrm{R}_{\mathrm{f}}$-PEG-g-PAA was physically integrated into the $\mathrm{R}_{\mathrm{f}}-\mathrm{PEG}-\mathrm{R}_{\mathrm{f}}$ micellar network, and the co-hydrogels remain physically cross-linked in three-dimensional micellar networks with long-term physical dispersion stability. Therefore, the co-hydrogel system is promising for drug delivery applications on mucosal surfaces.

Keywords: poly(ethylene glycol); fluoroalkyl; poly(acrylic acid); hydrogels; mucoadhesion; tensile strength; rheology; $\mathrm{pH}$ sensitivity

\section{Introduction}

Mucoadhesive biocompatible materials are desirable for localized drug-delivery applications on mucosal surfaces for maintaining sustained bioavailability of drugs [1-3]. Poly(ethylene glycol) (PEG)-based hydrogel materials with mucoadhesive properties are especially applicable due to PEG's biocompatibility [4-8]. It is known that acrylic-based polymers have high adhesive bond strengths with mucus [9-11]. Therefore, hydrogels containing poly(acrylic acid) (PAA) are among the most recognized mucoadhesive systems and have been widely used in topical and oral drug deliveries [12,13]. In addition, PAA based polymers exhibit $\mathrm{pH}$ response [14,15]. Mucus is a viscous, adherent secretion which lines all body cavities exposed to the external environment. The main component of mucus are mucins, which are a class of high molecular weight $\left(0.5 \times 10^{6}\right.$ to $\left.20 \times 10^{6}\right)$ glycoproteins $[16,17]$. Mucins are responsible for the viscoelastic gel-like property of mucus, and for the adhesive interaction with the PAA component.

Hydrogels are three-dimensional (3D) networks formed by cross-linked hydrophilic polymers $[8,15,18,19]$. The crosslinking agents, either physical or chemical, are essential to stabilize the hydrogels against solubilization when swelling in aqueous solutions [20-22]. It is challenging to maintain a physically cross-linked hydrogels with long-term stability 
in water compared to those which are chemically cross-linked. Therefore, physically cross-linked hydrogels with self-assembled gel phase in equilibrium with the sol phase are important for sustained drug release. Physically cross-linked hydrogels formed by self-assembly of fluoroalkyl double-ended poly(ethylene glycol) (previously abbreviated as double-ended $R_{\mathrm{f}}-\mathrm{PEG}$, here referred to as $\mathrm{R}_{\mathrm{f}}-\mathrm{PEG}-\mathrm{R}_{\mathrm{f}}$ ) have been reported to have such a property [23-25]. It was shown that the gel's concentration and viscoelastic property vary with the PEG midblock length and the $\mathrm{R}_{\mathrm{f}}$-end group's molecular weight. An interesting feature of this system is that the gel phase can maintain equilibrium composition in water with surface erosion. In this study, a co-hydrogel system with the properties of sol-gel two-phase coexistence and mucoadhesion has been developed based on the combined properties of $R_{\mathrm{f}}-\mathrm{PEG}-\mathrm{R}_{\mathrm{f}}$ and acrylic acid-based polymers, respectively. We have synthesized an $R_{\mathrm{f}}$-PEG-g-PAA (where g denotes grafted) copolymer and integrated it into the $\mathrm{R}_{\mathrm{f}}$-PEG$R_{f}$ hydrogel network through self-assembly. Our experimental data show that the $R_{f-}$ PEG- $R_{\mathrm{f}} / \mathrm{R}_{\mathrm{f}}$-PEG-g-PAA co-hydrogel system possesses both gel moduli and mucoadhesive properties. Therefore, the co-hydrogel system is promising to be developed as a drugdelivery platform for sustained drug deliveries on mucosal surfaces.

Formation of the $R_{\mathrm{f}}$-PEG- $\mathrm{R}_{\mathrm{f}}$ gel network is attributed to the $\mathrm{R}_{\mathrm{f}}$-groups that are both hydrophobic and lipophobic. The $\mathrm{R}_{\mathrm{f}}$-groups at both ends of the PEG chains fold together to form the hydrophobic cores of the micelles, meanwhile pairs of $R_{\mathrm{f}}$-groups of other $\mathrm{R}_{\mathrm{f}}$-PEG- $\mathrm{R}_{\mathrm{f}}$ chains associate with the $\mathrm{R}_{\mathrm{f}}$-cores to crosslink the neighboring micelles to form a micellar network in an aqueous environment. Results of a SANS (small angle neutron scattering) experiment shows that $\mathrm{R}_{\mathrm{f}}-\mathrm{PEG}-\mathrm{R}_{\mathrm{f}}$ formed a soft ordered lattice in water [24]. In this study, we hypothesized that the $R_{\mathrm{f}}$-group of the $\mathrm{R}_{\mathrm{f}}$-PEG-g-PAA can self-assemble with the $\mathrm{R}_{\mathrm{f}}$-cores of the $\mathrm{R}_{\mathrm{f}}$-PEG- $\mathrm{R}_{\mathrm{f}}$ micelles. Therefore, the gel-surface extruding PAA blocks of the co-hydrogel can interact with mucin, resulting in mucoadhesive properties. Assembly of the co-hydrogel system and its interaction with a mucus membrane is schematically shown in the graphical abstract of this paper. As will be demonstrated in this paper, the $\mathrm{R}_{\mathrm{f}}-\mathrm{PEG}-\mathrm{R}_{\mathrm{f}} / \mathrm{R}_{\mathrm{f}}$-PEG-g-PAA can self-assemble to form a co-hydrogel. It is interesting that the co-hydrogel materials are also soluble in many organic solvents such as methanol and dichloromethane. Therefore, the co-hydrogel system allows for flexible formulation of drugloaded, or nanoscale drug carrier-loaded, compositions for drug-delivery applications.

Tensile strength testing has been used to study the interactions between the mucoadhesive materials and mucosal surfaces [14,26-28]. In this study, we have also applied this method to study the adhesive interactions between $R_{f}-P E G-R_{f} / R_{f}-P E G-g-P A A$ cohydrogels with the surfaces of an artificial mucus made of porcine stomach mucin Type II and a pig small intestine, respectively. Rheological methods are informative to understand the physical and chemical cross-linkages and mechanical properties of hydrogels [29-35]. Therefore, we have used rheological methods to study the co-hydrogel system with presets of shear strain and frequency deformation. The results revealed the structural integrities of the co-hydrogels with various amounts of $R_{f}$-PEG-g-PAA integrated in the $R_{f}-P E G-R_{f}$ hydrogel networks in different $\mathrm{pH}$ conditions.

\section{Materials and Methods}

\subsection{Materials}

Polyethylene glycol (abbreviated as PEG, molecular weight $(\mathrm{MW})=6.0 \times 10^{3}$, CAS Number 25322-68-3), poly(acrylic acid) (abbreviated as PAA, MW $=1.8 \times 10^{3}$, CAS Number 9003-01-4), $1 \mathrm{~h}, 1 \mathrm{~h}, 2 \mathrm{~h}, 2 \mathrm{~h}$-perfluorooctanol (abbreviated as $\mathrm{R}_{\mathrm{f}} \mathrm{OH}$, CAS Number 647-42-7), isophorone diisocyanate (abbreviated as IPDI, CAS Number 4098-71-9), dibutyltin dilaurate (abbreviated as DBTDL, CAS Number 77-58-7), Tetrahydrofuran (abbreviated as THF), anhydrous (CAS Number 109-99-9), 3-Indoleacrylic acid (abbreviated as IAA, CAS Number 1204-06-4), methanol-d4 (CAS Number 811-98-3) and porcine stomach mucin Type II (CAS Number 84082-64-4) were all purchased from Sigma-Aldrich, St. Louis, MI, USA. Reagent grade solvents including ethylene glycol dimethyl ether anhydrous (commonly called glyme, CAS Number 110-71-4), diethyl ether anhydrous (CAS Number 60-29-7), 
methanol (CAS Number 67-56-1), hexane (HPLC grade, CAS Number 110-54-3), 1-ethyl3-(3-dimethylaminopropyl) carbodiimide hydrochloride (abbreviated as EDC-HCl, CAS Number 25952-53-8), $n$-hydroxysuccinimide (abbreviated as NHS, CAS Number 6066-82-6), $n, n$-diisopropylethylamine (abbreviated as DIEA, CAS Number7087-68-5), and anhydrous dimethylformamide (abbreviated as DMF, CAS Number 68-12-2) were all obtained from Fisher Scientific, Hampton, NH, USA. Sodium hydroxide (CAS Number 1310-73-2), sodium phosphate dibasic anhydrous (CAS Number 7558-79-4), sodium phosphate monobasic anhydrous (CAS Number 7558-80-7), Slide-A-Lyzer (7.0 K MWCO) dialysis cassette (Catalog No. PI66710) were all obtained from Fisher Scientific, USA. The PEG and $\mathrm{R}_{\mathrm{f}}-\mathrm{OH}$ were further dried under a high vacuum, and IPDI was further purified through vacuum distillation before use. We prepared $5 \mathrm{wt} \%$ artificial mucus through dissolving $0.5 \mathrm{~g}$ mucin in $9.5 \mathrm{~mL}$ buffer in a $50 \mathrm{~mL}$ Falcon tube followed by a vortex for 15 mins. Afterwards, the artificial mucus was annealed for $1 \mathrm{~h}$ before use. A pig small intestine was provided by BioreclamationIVT, Westbury, NY, USA. The small intestine was rinsed with water before shipped to our lab in frozen state.

\subsection{Synthesis of Double Ended $R_{f}$-PEG (Fluoroalkyl Double-Ended Poly(Ethylene Glycol) $\left.\left(R_{f}-P E G-R_{f}\right)\right)$}

PEG with MW $=6.0 \times 10^{3}$ and the $\mathrm{R}_{\mathrm{f}}$-OH were used to synthesize $\mathrm{R}_{\mathrm{f}}$-PEG- $\mathrm{R}_{\mathrm{f}}$. Procedure for the synthesis has been described in other's and our previous publications $[23,24,36-39]$. Briefly, the interconnection of the $\mathrm{R}_{\mathrm{f}}-\mathrm{OH}$ alcohol group with both PEG's $\mathrm{OH}$ ends were attained through the IPDI linker. The $\mathrm{R}_{\mathrm{f}}$-IPMU (isophorone monourethane) intermediate was first obtained through the reaction of the $\mathrm{R}_{\mathrm{f}}-\mathrm{OH}$ with an excess molar amount of IPDI. To produce the $\mathrm{R}_{\mathrm{f}}-\mathrm{PEG}-\mathrm{R}_{\mathrm{f}}$ polymer, freshly vacuum-dried PEG and an excess molar amount of $\mathrm{R}_{\mathrm{f}}$-IPMU were dissolved in glyme, and a few drops of DBTDL were added to catalyze the reaction followed by purification. A yield of $76 \%$ was obtained. The route of synthesis was given in Scheme S1 of the supplementary file.

\subsection{Synthesis of $R_{f}-P E G-g-P A A$ (Poly(Acrylic Acid))}

The $\mathrm{R}_{\mathrm{f}}$-PEG-OH was obtained through the same procedure as that of $\mathrm{R}_{\mathrm{f}}-\mathrm{PEG}-\mathrm{R}_{\mathrm{f}}$, but with the molar ratio of $R_{f}$-IPMU to PEG adjusted between 1 and 2 . The yield of the $R_{\mathrm{f}}$-PEG$\mathrm{OH}$ product was $\sim 78 \%$. The $\mathrm{R}_{\mathrm{f}}-\mathrm{PEG}-\mathrm{OH}$ was then grafted to the PAA. Briefly, $0.1 \mathrm{mmol}$ $(0.180 \mathrm{~g})$ of PAA, $0.15 \mathrm{mmol}(0.029 \mathrm{~g})$ of EDC- $\mathrm{HCl}$, and $0.15 \mathrm{mmol}(0.017 \mathrm{~g})$ of NHS were dissolved in $6 \mathrm{~mL}$ anhydrous DMF in a $25 \mathrm{~mL}$ round bottom flask. The solution was then stirred at room temperature overnight to form the PAA-NHS ester. Then, $0.1 \mathrm{mmol}(0.659 \mathrm{~g})$ $\mathrm{R}_{\mathrm{f}}$-PEG-OH (average molecular weight, $\left.\mathrm{MW}=6586.41\right), 0.25 \mathrm{mmol}(0.0323 \mathrm{~g})$ of DIEA, and another $6 \mathrm{~mL}$ anhydrous DMF were added into the PAA-NHS ester solution. The solution was stirred for four days at room temperature to obtain the grafted $\mathrm{R}_{\mathrm{f}}-\mathrm{PEG}-\mathrm{g}$ PAA copolymer. Route of the synthesis is shown in Scheme S2 of the supplementary file. Dialysis was used to purify the product, and lyophilization was used to obtain the product, $\mathrm{R}_{\mathrm{f}}$-PEG-g-PAA. The yield was found to be $\sim 65 \%$.

\subsection{Preparation of the $R_{f}-P E G-R_{f}$ and $R_{f}-P E G-g-P A A$ Co-Hydrogels}

A homogeneous solid mixture of $R_{\mathrm{f}}$-PEG-g-PAA and $\mathrm{R}_{\mathrm{f}}$-PEG- $\mathrm{R}_{\mathrm{f}}$ was made by dissolving both in methanol and then lyophilizing it overnight. The lyophilized solid powder was compressed to a tablet followed by being immersed in water or other buffer solutions. For example, a tablet of $320 \mathrm{mg}$ of the dried $5 \mathrm{wt} \% \mathrm{R}_{\mathrm{f}}$-PEG-g-PAA and $95 \mathrm{wt} \% \mathrm{R}_{\mathrm{f}}-\mathrm{PEG}-\mathrm{R}_{\mathrm{f}}$ mixture was placed in $11.0 \mathrm{~mL}$ DI water $(\mathrm{pH}=4-5$ due to the PAA), $11.0 \mathrm{~mL}$ phosphatebuffered saline (PBS) buffer ( $\mathrm{pH}=7.2$ ), or $11.0 \mathrm{~mL}$ Glycine/ $\mathrm{NaOH}$ buffer $(\mathrm{pH}=10.6)$. Seven days were used to homogenize the co-hydrogel at $37^{\circ} \mathrm{C}$. The gel phase was separated from the sol phase using an automatic pipette. Table 1 summarizes the compositions of $R_{\mathrm{f}}$-PEG-g-PAA, and $\mathrm{R}_{\mathrm{f}}$-PEG- $\mathrm{R}_{\mathrm{f}}$ for making the co-hydrogels. PAA was also used to mix with the $R_{\mathrm{f}}-\mathrm{PEG}-\mathrm{R}_{\mathrm{f}}$ as a control experiment to prove the association of the $\mathrm{R}_{\mathrm{f}}$-group in the $R_{f}$-PEG-g-PAA with the $R_{f}$-cores of the $R_{f}$-PEG- $R_{f}$ micelles in the tensile strength 
test. Deionized (DI) water, PBS, glycine/ $\mathrm{NaOH}$ buffer solution were used to make the co-hydrogels.

Table 1. Compositions of $\mathrm{R}_{\mathrm{f}}$-PEG-g-PAA, $\mathrm{R}_{\mathrm{f}}-\mathrm{PEG}-\mathrm{R}_{\mathrm{f}}$ (fluoroalkyl double-ended poly(ethylene glycol)), and PAA (poly(acrylic acid)) in the lyophilized solid mixtures to make the co-hydrogels.

\begin{tabular}{cccc}
\hline Composition \# & $\mathbf{R}_{\mathbf{f}}$-PEG- $\mathbf{R}_{\mathbf{f}} \mathbf{w t} \mathbf{0}$ & $\mathbf{R}_{\mathbf{f}}$-PEG-g-PAA $\mathbf{w t} \%$ & PAA $\mathbf{w t} \mathbf{~}$ \\
\hline 1 & 100.0 & 0.0 & 0.0 \\
2 & 95.0 & 5.0 & 0.0 \\
3 & 92.5 & 7.5 & 0.0 \\
4 & 90.0 & 10.0 & 0.0 \\
5 & 87.5 & 12.5 & 0.0 \\
6 & 85.0 & 15.0 & 0.0 \\
7 & 80.0 & 20.0 & 0.0 \\
$* 8$ & 95.0 & 0.0 & 5.0 \\
$* 9$ & 90.0 & 0.0 & 10.0 \\
$* 10$ & 0.0 & 5.0 & 0.0 \\
$* 11$ & 0.0 & 10.0 & 0.0 \\
\hline
\end{tabular}

* Note: In composition \#8, the $5.0 \%$ PAA is corresponding to the mass amount of PAA block in composition \#2. The actual percentage is $0.9 \%$ PAA and $99.1 \% \mathrm{R}_{\mathrm{f}}-\mathrm{PEG}-\mathrm{R}_{\mathrm{f}}$. Similarly, in composition \#9, the $10.0 \%$ PAA is corresponding to the amount of PAA block in composition \#4. The actual percentage is $1.9 \%$ PAA and $98.1 \% R_{f}-P E G-R_{f}$. In composition \#10, 5.0\% $\mathrm{R}_{\mathrm{f}}$-PEG-g-PAA is corresponding to the amount of $\mathrm{R}_{\mathrm{f}}$-PEG-g-PAA in composition \#2 but without $R_{\mathrm{f}}$-PEG- $\mathrm{R}_{\mathrm{f}}$. In composition $\# 11,10.0 \% \mathrm{R}_{\mathrm{f}}$-PEG-g-PAA is corresponding to the amount of $\mathrm{R}_{\mathrm{f}}$-PEG-g-PAA in composition \#4 but without $\mathrm{R}_{\mathrm{f}}-\mathrm{PEG}-\mathrm{R}_{\mathrm{f}}$.

\subsection{Molecular Weight and Structural Characterizations Using Matrix-Assisted Laser Desorption/Ionization-Time of Flight (MALDI-TOF) Mass Spectrometry (MS) and Nuclear Magnetic Resonance (NMR) Instruments}

Matrix-assisted laser desorption/ionization-time of flight (MALDI-TOF) is a soft ionization technique that enables the measurement of molecular weight distribution of polymers [40]. Both number average molecular weight $\left(\mathrm{M}_{\mathrm{n}}\right)$ and mass average molecular weight $\left(M_{w}\right)$, thus the polydispersity indexes $\left(\mathrm{PDI}=\mathrm{M}_{\mathrm{w}} / \mathrm{M}_{\mathrm{n}}\right)$ can be determined from the mass distribution of the spectra [41]. A MALDI-TOF mass spectrometry (MS) instrument, Voyager-DE STR, (Applied Biosystems, Waltham, MA, UAS), was used to characterize PEG, $R_{\mathrm{f}}-\mathrm{PEG}-\mathrm{R}_{\mathrm{f}}, \mathrm{R}_{\mathrm{f}}-\mathrm{PEG}-\mathrm{OH}$ and $\mathrm{R}_{\mathrm{f}}$-PEG-g-PAA. To undertake the MS experiment, $0.25 \mathrm{M}$ $\mathrm{M}$ indole-3-acetic acid (IAA) in THF solvent was prepared as the matrix solution. $10 \mathrm{~g} / \mathrm{L}$ concentrations of the polymer solutions were made in DI water for PEG, and in methanol for $\mathrm{R}_{\mathrm{f}}-\mathrm{PEG}-\mathrm{R}_{\mathrm{f}}, \mathrm{R}_{\mathrm{f}}-\mathrm{PEG}-\mathrm{OH}$, and $\mathrm{R}_{\mathrm{f}}-\mathrm{PEG}-\mathrm{g}-\mathrm{PAA}$. Volume ratio of 1:1 of the sample solution to the matrix solution was used. One $\mu \mathrm{L}$ of the mixed solution was loaded into a well of the MOLDI-TOF plate. ${ }^{1} \mathrm{H}$ NMR (nuclear magnetic resonance) spectra were acquired using a Bruker BioSpin Avance ${ }^{\mathrm{I}}$ (Billerica, MA, USA) $400 \mathrm{MHz}$ NMR instrument to characterize the structure of $\mathrm{R}_{\mathrm{f}}$-PEG-g-PAA. Methanol- $\mathrm{d}_{4}\left(\mathrm{CD}_{3} \mathrm{OD}\right)$ was used as the NMR solvent.

\subsection{Mucoadhesion Study by Tensile Strength Method}

Investigation of the mucoadhesive bond strength between the surfaces of the cohydrogels and the surfaces of the artificial mucus and the pig small intestine was carried out using the tensiometric technique [14,26-28]. In a typical tensile experiment, the force necessary for detachment of the two surfaces is recorded as a function of elongation observed at the polymer-mucus interface. The stress is equal to the force divided by the total initial area, and the work of adhesion is calculated as the area under the force-elongation curves. Here, we compared the maximum detachment stresses (MDSs) (maximum forces required to separate the two surfaces divided by the areas) among the different compositions of the co-hydrogels with the mucosal surfaces. A TA.XTplus texture analyzer (Stable Micro Systems, Godalming, Surrey, UK) was used for doing the experiments and the Exponent software from Stable Micro Systems was used for analyzing the data. For the mucoadhesion study with the mucus made of the porcine stomach mucin Type II [42], a super strong waterproof black adhesive double-sided foam mounting tape was used. 
A piece of $25 \mathrm{~mm} \times 25 \mathrm{~mm}$ of the double-sided tape was placed on the center of the platform (bottom), and then covered with a $25 \mathrm{~mm} \times 25 \mathrm{~mm}$ filter paper. Also, a piece of $10 \mathrm{~mm} \times 10 \mathrm{~mm}$ double-sided tape was adhered to the center of the round probe (top) to which $10 \mathrm{~mm} \times 10 \mathrm{~mm}$ filter paper was mounted (see Figure S1 in the Supplementary Information.) A $30 \mu \mathrm{L}$ co-hydrogel sample was placed onto the $10 \mathrm{~mm} \times 10 \mathrm{~mm}$ filter paper, and a $185 \mu \mathrm{L}$ mucus sample was applied onto the $25 \mathrm{~mm} \times 25 \mathrm{~mm}$ filter paper. The samples were allowed to homogenize for $5 \mathrm{~min}$ in the filter papers before running each test. For the mucoadhesion study with the pig small intestine, a $25 \mathrm{~mm} \times 25 \mathrm{~mm}$ pig small intestine tissue with internal surface (the surface covered with mucosal layer) up was placed on the surface of the texture analyzer's platform [14,43]. A zinc plated cut washer with $3 / 8$ inches in inner-diameter was placed on top of the small intestine sample to secure the pig small intestine tissue sticking on the platform surface (see Figure S2). A 0.5 inch in diameter double sided tape was adhered to the center of the TA-10 probe. The bottom side of the double sided tape was covered with a 0.5 inch in diameter filter paper, which was then soaked with the co-hydrogel sample (see Figure S2). When running the tensile strength experiment, once a trigger force of $150 \mathrm{~g}$ was detected on the surface of the sample, the probe proceeded to compress the sample until a $250 \mathrm{~g}$ force was reached. The force is then held for $60 \mathrm{~s}$ to let the co-hydrogels have enough contact time with the mucus surface. The probe then withdrew to a maximum distance of $11 \mathrm{~mm}$ above the sample. The test of each sample was repeated at least 4 times to ensure repeatability.

\subsection{Rheological Measurements}

Rheological measurements were carried out using a modular compact Rheometer (MCR 302, Anton Paar GmbH, Graz, Austria). An electrically heated plate temperature system was set at $37^{\circ} \mathrm{C}$ to mimic human physiological temperature. To prevent the wallspill effect, a $25 \mathrm{~mm}$ diameter sandblasted parallel plate (PP25/S, Anton Paar) geometry was used. The hydrogel sample was placed between the two plates, and the width of the gap between the parallel plates was set to $0.5 \mathrm{~mm}$. A solvent trap device was used to prevent the evaporation of water in the hydrogels. Two minutes were used to homogenize the sample temperature before starting the tests. Shear strain amplitude sweeps and frequency sweeps were carried out to characterize the viscoelastic properties of the co-hydrogels. Shear stress versus shear strain curves and moduli versus shear strain curves were acquired by shear strain amplitude sweeps using a low frequency of $10 \mathrm{~s}^{-1}$. The frequency sweeps were carried out to measure $G^{\prime}$ and $G^{\prime \prime}$ moduli as functions of angular frequency ranging from $100 \mathrm{rad} / \mathrm{s}$ to $0.1 \mathrm{rad} / \mathrm{s}$. A shear strain of $1 \%$ in the linear viscoelastic (LVE) range was used during the frequency sweep. The measurements were carried out using logarithmic steps and the corresponding logarithmic scale was also plotted to illustrate the values in both small and large scales.

\section{Results and Discussion}

\subsection{Chemical Analysis of the Product}

MALDI-TOF MS spectrum of the PEG is shown in Figure S3, and that of the $R_{f}-P E G-R_{f}$ is shown in Figure S4. The average molecular weight of the PEG was determined to be $6.2 \times 10^{3}(\mathrm{PDI}=1.005)$, and that of the $\mathrm{R}_{\mathrm{f}}-\mathrm{PEG}-\mathrm{R}_{\mathrm{f}}$ to be $\sim 7.4 \times 10^{3}(\mathrm{PDI}=1.006)$, showing the successful synthesis of the $\mathrm{R}_{\mathrm{f}}-\mathrm{PEG}-\mathrm{R}_{\mathrm{f}}$. The MALDI TOF MS spectrum of the $\mathrm{R}_{\mathrm{f}}-\mathrm{PEG}-\mathrm{OH}$ is shown in Figure S5. The molecular weight of this intermediate is $\sim 6.8 \times 10^{3}(\mathrm{PDI}=1.007)$ showing the produced $\mathrm{R}_{\mathrm{f}}$-PEG-OH. The MALDI TOF MS spectrum of the $\mathrm{R}_{\mathrm{f}}$-PEG-g-PAA is shown in Figure S6, which has an average molecular weight of $8.0 \times 10^{3}(\mathrm{PDI}=1.011)$ showing the successful synthesis of the $\mathrm{R}_{\mathrm{f}}$-PEG-g-PAA product. Figure $\mathrm{S} 7$ shows the ${ }^{1} \mathrm{H}$ NMR spectrum of the $\mathrm{R}_{\mathrm{f}}$-PEG-g-PAA. The major peak at $3.5407 \mathrm{ppm}$ shows the PEG block, $-\left[\mathrm{CH}_{2} \mathrm{CH}_{2} \mathrm{O}\right]-$. The PAA ${ }^{1} \mathrm{H}$ signals are quite broadly distributed from $1.0 \mathrm{ppm}$ to $2.5 \mathrm{ppm}$ which can only be seen after the relative intensity of the spectrum is scrolled up. Figure S8 shows the comparison of the spectra of $\mathrm{R}_{\mathrm{f}}$-PEG-g-PAA (bottom, red) and PAA (top, blue) in the PAA region, which indicates the PAA block in the $\mathrm{R}_{\mathrm{f}}$-PEG-g-PAA copolymer. 


\subsection{Mucoadhesion by Tensile Tests}

Figure S9 shows the photos of the sol-gel two-phase coexistences of the $5 \% \mathrm{R}_{\mathrm{f}}$-PEGg-PAA/95\% $R_{f}-P E G-R_{f}$ (composition \#2), and the 10\% $R_{f}-P E G-g-P A A / 90 \% R_{f}-P E G-R_{f}$ (composition \#4), respectively, prepared in the following buffers or water at $37^{\circ} \mathrm{C}$ after 11 days: (A) and (B) in PBS buffer ( $\mathrm{pH}=7.2)$; (C) and (D) in DI water ( $\mathrm{pH}=4-5)$; and $(\mathrm{E})$ and $(\mathrm{F})$ in the glycine/sodium hydroxide buffer $(\mathrm{pH}=10.6)$. The volumes of the gel phases did not expand further after several days. These results demonstrate that the sol-gel two-phase coexistences in these buffers were retained after long incubation periods. The gel phases were used to conduct the mucoadhesion experiments.

Figure S10 shows the force (g) vs. time (s) curves for the 5.0\% mucin Type II artificial mucus sample interacting with the $\mathrm{R}_{\mathrm{f}}-\mathrm{PEG}-\mathrm{g}-\mathrm{PAA} / \mathrm{R}_{\mathrm{f}}-\mathrm{PEG}-\mathrm{R}_{\mathrm{f}}$ co-hydrogels (compositions \#2 to \#6 in Table 1) and the control samples (water, composition \#1 and compositions \#7 to \#10) prepared in water. The maximum detachment stresses (MDSs) $\left(\mathrm{g} / \mathrm{cm}^{2}\right)$ required to separate the two surfaces can be seen on the tops of the peaks divided by the surface area. To make the MDSs more visible, Figure S11 shows the relative MDSs with respect to the MDS of the water sample, i.e., the relative MDS = MDS (sample)-MDS (water). The MDS of the water sample with the artificial mucus sample is the lowest compared to all the other samples. The relative MDS increased with the increase of the $R_{f}$-PEG-g-PAA component until the sample of $15.0 \% \mathrm{R}_{\mathrm{f}}$-PEG-g-PAA/85.0\% $\mathrm{R}_{\mathrm{f}}-\mathrm{PEG}-\mathrm{R}_{\mathrm{f}}$ (composition \#6). After surpassing 15.0\% Rf-PEG-g-PAA, the relative MDS decreased as shown by the sample of $20.0 \% \mathrm{R}_{\mathrm{f}}$-PEG-g-PAA/80.0\% $\mathrm{R}_{\mathrm{f}}$-PEG- $\mathrm{R}_{\mathrm{f}}$ (composition \#7). The above result proves that with low $\mathrm{R}_{\mathrm{f}}$-PEG-g-PAA percentage, the $\mathrm{R}_{\mathrm{f}}$-PEG-g-PAA could be held strongly in the cohydrogel phase. The gel surface-bound PEG-g-PAA blocks protruded into the water phase to interact with mucin in the mucus phase. To see if the $R_{\mathrm{f}}$-group in $R_{\mathrm{f}}$-PEG-g-PAA truly played a role in holding the -PAA block on the surface of the co-hydrogel, experiments were performed using 5.0\% PAA/95.0\% $\mathrm{R}_{\mathrm{f}}-\mathrm{PEG}-\mathrm{R}_{\mathrm{f}}$ (composition \#8) and the $10.0 \%$ PAA/90.0\% $\mathrm{R}_{\mathrm{f}}-\mathrm{PEG}-\mathrm{R}_{\mathrm{f}}$ (composition \#9). As expected, the relative MDSs of these PAA/ $\mathrm{R}_{\mathrm{f}}-\mathrm{PEG}-\mathrm{R}_{\mathrm{f}}$ samples dramatically decreased compared to all the $R_{\mathrm{f}}-\mathrm{PEG}-\mathrm{g}-\mathrm{PAA} / \mathrm{R}_{\mathrm{f}}-\mathrm{PEG}-\mathrm{R}_{\mathrm{f}}$ samples. This result demonstrates that the $R_{f}$-groups in $R_{f}$-PEG-g-PAA physically associated with the $R_{f}$-cores of the $R_{f}-P E G-R_{f}$ micelles. To demonstrate the necessity of $R_{f}-P E G-R_{f}$, experiments were also performed with the $5.0 \% \mathrm{R}_{\mathrm{f}}$-PEG-g-PAA (composition \#10) and the $10.0 \% \mathrm{R}_{\mathrm{f}}$-PEGg-PAA (composition \#11) samples without $R_{f}-P E G-R_{f}$. Their relative MDSs are the smallest compared to all the other samples, proving that $\mathrm{R}_{\mathrm{f}}$-PEG-g-PAA formed a co-hydrogel with $\mathrm{R}_{\mathrm{f}}-\mathrm{PEG}-\mathrm{R}_{\mathrm{f}}$. In our opinion, it is difficult to give a regular range of MDS for mucoadhesion. In our opinion, besides the intrinsic mucoadhesive forces, the value of MDS also depends on the sample preparation in a study. Thus, comparison of the relative MDSs among a series of samples is more reliable than comparing data in publications of different authors.

Figure S12 shows the force vs. time curves for the 5.0\% mucin Type II artificial mucus sample interacting with the $\mathrm{R}_{\mathrm{f}}-\mathrm{PEG}-\mathrm{g}-\mathrm{PAA} / \mathrm{R}_{\mathrm{f}}-\mathrm{PEG}-\mathrm{R}_{\mathrm{f}}$ co-hydrogel and the control sample prepared in the PBS buffer. Figure S13 shows the corresponding relative MDSs with respect to the MDS of the PBS buffer sample. Figure S14 shows the force vs. time curves for the $5.0 \%$ mucin Type II artificial mucus sample interacting with the $R_{\mathrm{f}}-\mathrm{PEG}-\mathrm{g}-\mathrm{PAA} / \mathrm{R}_{\mathrm{f}}-\mathrm{PEG}-\mathrm{R}_{\mathrm{f}}$ co-hydrogel and the control sample prepared in the glycine/ $\mathrm{NaOH}$ buffer. Figure S15 shows the corresponding relative MDSs with respect to the MDS of the glycine/ $\mathrm{NaOH}$ buffer sample. The trends of the relative MDSs for the co-hydrogels in the PBS buffer and the glycine $/ \mathrm{NaOH}$ buffer are the same as those of the co-hydrogel samples prepared in water.

Figure S16 shows the force vs. time curves of the interactions of various $\mathrm{R}_{\mathrm{f}}-\mathrm{PEG}-\mathrm{g}$ $\mathrm{PAA} / \mathrm{R}_{\mathrm{f}}-\mathrm{PEG}-\mathrm{R}_{\mathrm{f}}$ co-hydrogels and the control samples prepared in water with the pig small intestine. Figure S17 shows the corresponding bar graph presentation of the relative MDSs with respect to the water sample. The trends of the relative MDSs are the same as those of the co-hydrogel samples interacting with the mucus sample. The $R_{f}-P E G-R_{f}$ hydrogel alone, the $\mathrm{R}_{\mathrm{f}}$-PEG-g-PAA hydrogel alone, and the $\mathrm{R}_{\mathrm{f}}-\mathrm{PEG}-\mathrm{R}_{\mathrm{f}}$ hydrogel mixed with PAA also showed much lower MDSs compared to the $R_{f}-P E G-g-P A A / R_{f}-P E G-R_{f}$ 
co-hydrogel samples. Figure S18 shows the force vs. time curves of the interactions of various $\mathrm{R}_{\mathrm{f}}$-PEG-g-PAA/ $\mathrm{R}_{\mathrm{f}}-\mathrm{PEG}-\mathrm{R}_{\mathrm{f}}$ co-hydrogels and the control sample prepared in the PBS buffer with the pig small intestine. Figure S19 shows the corresponding bar graph presentation showing the corresponding relative MDSs. Figure S20 shows the force vs. time curves of the interactions of various $\mathrm{R}_{\mathrm{f}}$-PEG-g-PAA/ $\mathrm{R}_{\mathrm{f}}-\mathrm{PEG}-\mathrm{R}_{\mathrm{f}}$ co-hydrogels and the control sample prepared in the glycine/ $\mathrm{NaOH}$ buffer with the pig small intestine surface. Figure S21 shows the corresponding bar graph showing the relative MDSs. The trend of $\mathrm{pH}$ influence on MDS is the same as that seen in the experiments with the artificial mucus.

Figure 1a shows the comparison of the relative MDSs of the interactions between the $\mathrm{R}_{\mathrm{f}}$-PEG-g-PAA $/ \mathrm{R}_{\mathrm{f}}-\mathrm{PEG}-\mathrm{R}_{\mathrm{f}}$ co-hydrogel samples and the artificial mucus surface prepared in water and the buffers. Figure $1 \mathrm{~b}$ shows the comparison of the relative MDSs of the interactions between the $R_{\mathrm{f}}$-PEG-g-PAA/ $\mathrm{R}_{\mathrm{f}}-\mathrm{PEG}-\mathrm{R}_{\mathrm{f}}$ hydrogel samples prepared in water and the buffers and the pig small intestine surface. The MDSs in both Figure $1 \mathrm{a}$ and $\mathrm{b}$ have the same trend. It shows that the adhesion forces of the co-hydrogels made in the glycine $/ \mathrm{NaOH}$ buffer $(\mathrm{pH}=10.6)$ and water $(\mathrm{pH}=4-5)$ are larger than those made in the PBS buffer $(\mathrm{pH}=7.2)$. Thus, the $\mathrm{R}_{\mathrm{f}}-\mathrm{PEG}-\mathrm{g}-\mathrm{PAA} / \mathrm{R}_{\mathrm{f}}-\mathrm{PEG}-\mathrm{R}_{\mathrm{f}}$ co-hydrogels showed $\mathrm{pH}$-sensitive mucoadhesion. The $\mathrm{pH}$ sensitivity indicates that hydrogen-bonding and electrostatic interactions between the PAA and the mucin played the major roles in the adhesions.

\subsection{Gel Structural Integrity by Rheological Analysis \\ 3.3.1. Shear Strain Amplitude Sweep}

Amplitude sweep test provides information about the integrities/destructions of the internal structures of hydrogels at the preset shear strains or shear stresses. Figure 2 shows the shear stress versus shear strain curves (in logarithmic scales) for the given co-hydrogels prepared in water (a), PBS buffer (b) and glycine/ $\mathrm{NaOH}$ buffer (c). Here, the shear strains (deformation of the co-hydrogel) are the preset in descending logarithmic steps, and the shear stresses were the responses to the shear strains. There are two regions in each of the curves. One is the initial linear-elastic (LE) region where the low shear stress increases linearly with the increase of the low shear strain. The other region is the flow region where the shear stress is off the LE curve. After the co-hydrogels could no longer sustain the added stress within the elastic limit, they yielded to the stress and, therefore, flowed. The cross-over point between the LE region and the flow region is referred to as the yield point. The co-hydrogels showed physically cross-linked gel structures before the yield points, but showed fluidic structures after the yield points. The yield points were approximately shown as the intersections of the stress-strain curves with the straight line in each of the Figures. Both the shear strain and shear stress at the yield points decreased with the increase of the $\mathrm{R}_{\mathrm{f}}$-PEG-g-PAA portion from $~ 10 \%$ shear strain for the $100 \% \mathrm{R}_{\mathrm{f}}-\mathrm{PEG}-\mathrm{R}_{\mathrm{f}}$ samples (composition \#1 in Table 1) to $4 \%$ shear strain for the $12.5 \% \mathrm{R}_{\mathrm{f}}$-PEG-g-PAA $/ 87.5 \%$ $\mathrm{R}_{\mathrm{f}}-\mathrm{PEG}-\mathrm{R}_{\mathrm{f}}$ samples (composition \#5 in Table 1 ). In the LE regions, shear strain deformations of the co-hydrogels were small enough so that the gel networks were conserved. However, in the flow region, the larger shear strains dragged the $\mathrm{R}_{\mathrm{f}}$-cores apart, which subsequently destroyed the hydrogel networks resulting in fluidic solutions of the polymers. After shear strain surpassed the yield point, the shear stress no longer followed the LE trend. In fact, most of the shear stresses even decreased with the increase of the shear strain in the flow regions due to the continued breakdown of the remaining hydrogel network. The shear stresses decreased with the increase of the $\mathrm{R}_{\mathrm{f}}$-PEG-g-PAA portion for all the hydrogels prepared in water and the buffers, which indicates the decreased strengths of the crosslinkages between the micelles due to the reduced number of cross-linkages between the micelles through the $R_{\mathrm{f}}-\mathrm{PEG}-\mathrm{R}_{\mathrm{f}}$ chains. As the portion of Rf-PEG-g-PAA increases, the $\mathrm{R}_{\mathrm{f}}-$ groups of $R_{f}$-PEG-g-PAA polymers replaced more of the $R_{f}$-groups of $R_{f}-P E G-R_{f}$ polymers which tether the micelle cores together. This experimental phenomenon demonstrates that the $R_{f}$-groups of $R_{f}$-PEG-g-PAA incorporated into the $R_{f}$-cores formed by $R_{f}-P E G-R_{f}$. Small-angle neutron scattering (SANS) results show that the aggregation numbers of the 
$R_{f}$-groups in the $R_{f}-P E G-R_{f}$ hydrogels were definite for each combination of the $R_{f}$-group's molecular weights and PEG's lengths [24]. Our conclusion makes sense providing that the $\mathrm{R}_{\mathrm{f}}$-core aggregation number kept unchanged with the incorporation of the $\mathrm{R}_{\mathrm{f}}$-groups of $\mathrm{R}_{\mathrm{f}}$-PEG-g-PAA. It is also noticed that the shear stresses have the following general order: hydrogels prepared in the PBS buffer $(\mathrm{pH}=7.2)>$ those prepared in the glycine $/ \mathrm{NaOH}$ buffer $(\mathrm{pH}=10.6)>$ those prepared in water $(\mathrm{pH}=4-5)$. Stronger shear stress shows stronger gel network interconnection. We will return to discuss the $\mathrm{pH}$ dependent shear stress together with the $\mathrm{pH}$ dependent moduli in the flowing paragraphs.

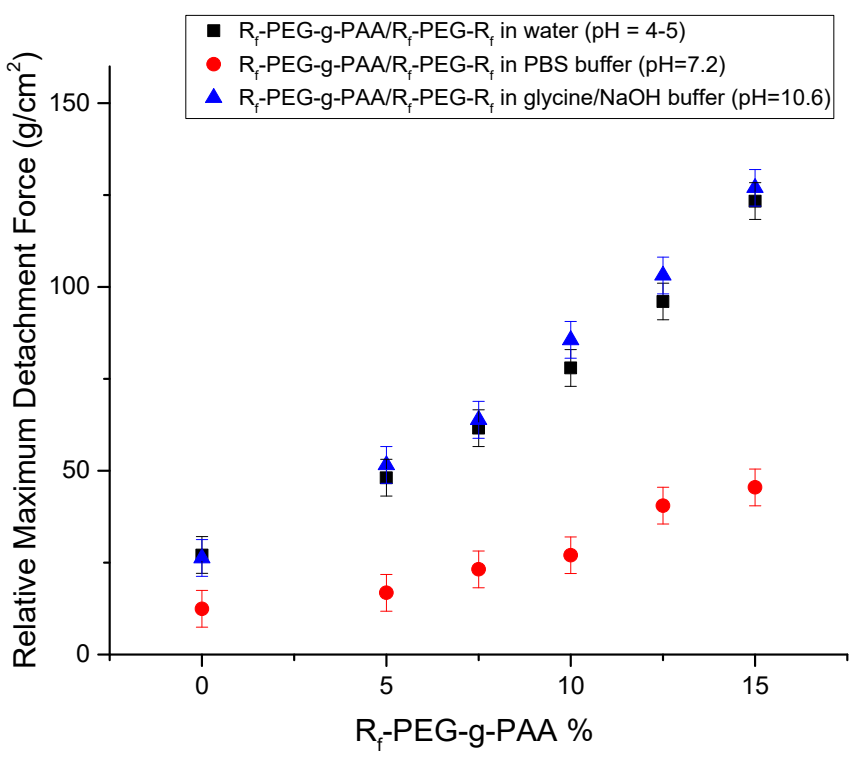

(a)

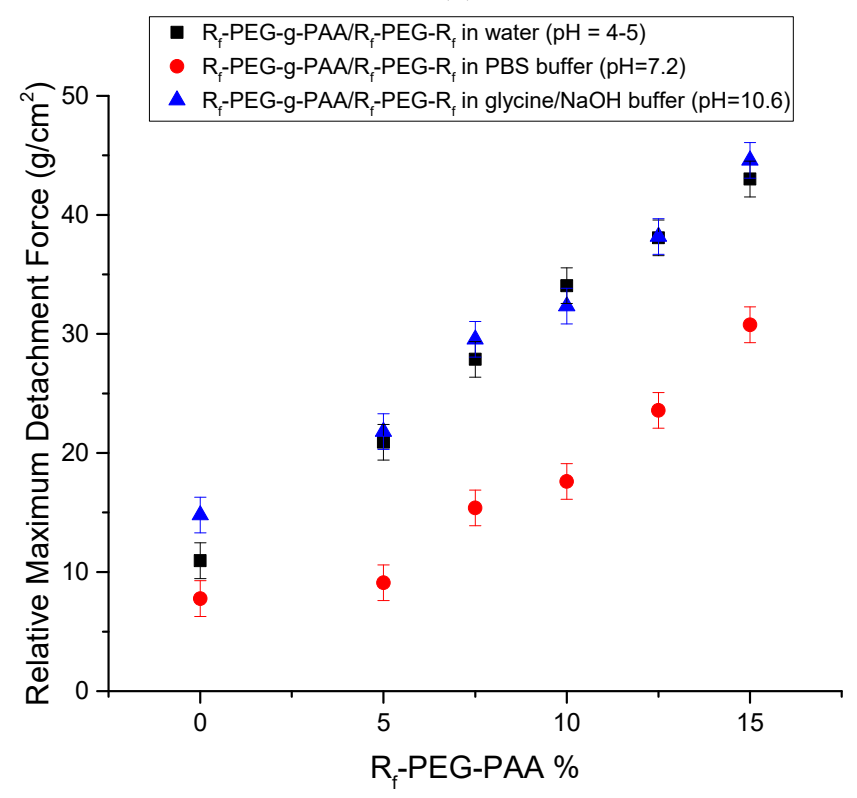

(b)

Figure 1. (a) Comparison of relative maximum detachment stresses (MDSs) of the interactions between the $\mathrm{R}_{\mathrm{f}}$-PEG-g-PAA/ $\mathrm{R}_{\mathrm{f}}-\mathrm{PEG}-\mathrm{R}_{\mathrm{f}}$ samples and the mucus samples prepared in different buffers (shown in the inset). (b) Comparison of the relative MDSs of the interactions between the $\mathrm{R}_{\mathrm{f}}$-PEG-g$\mathrm{PAA} / \mathrm{R}_{\mathrm{f}}-\mathrm{PEG}-\mathrm{R}_{\mathrm{f}}$ samples prepared in different buffers (shown in the inset) and the pig small intestine surface. 


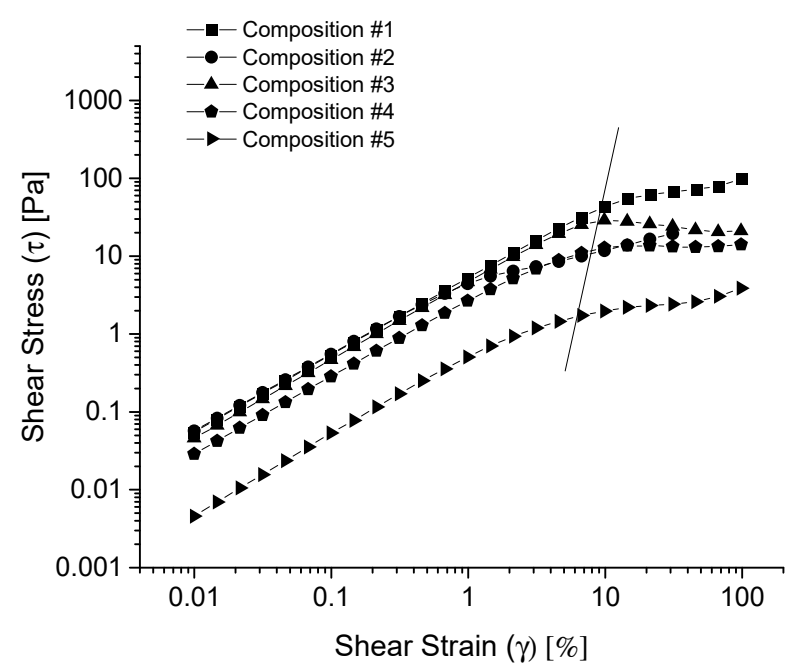

(a)

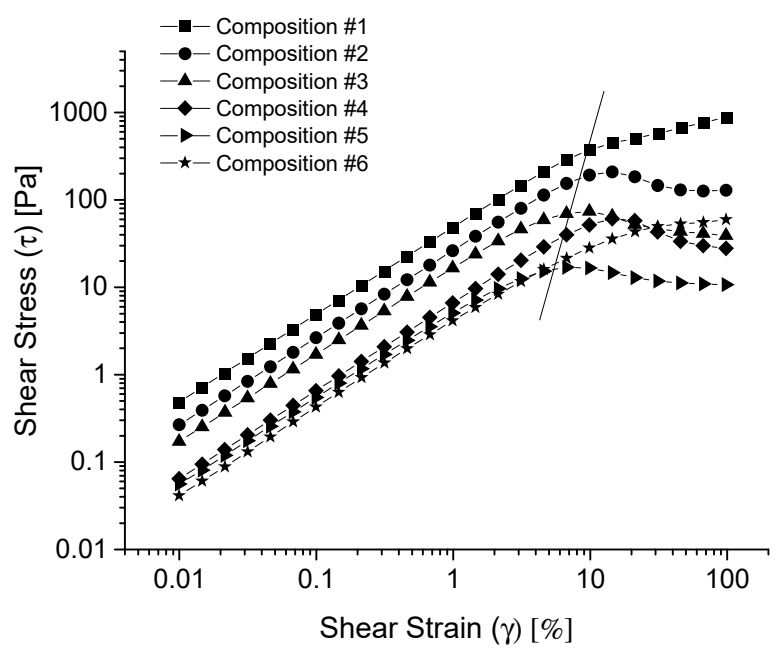

(b)

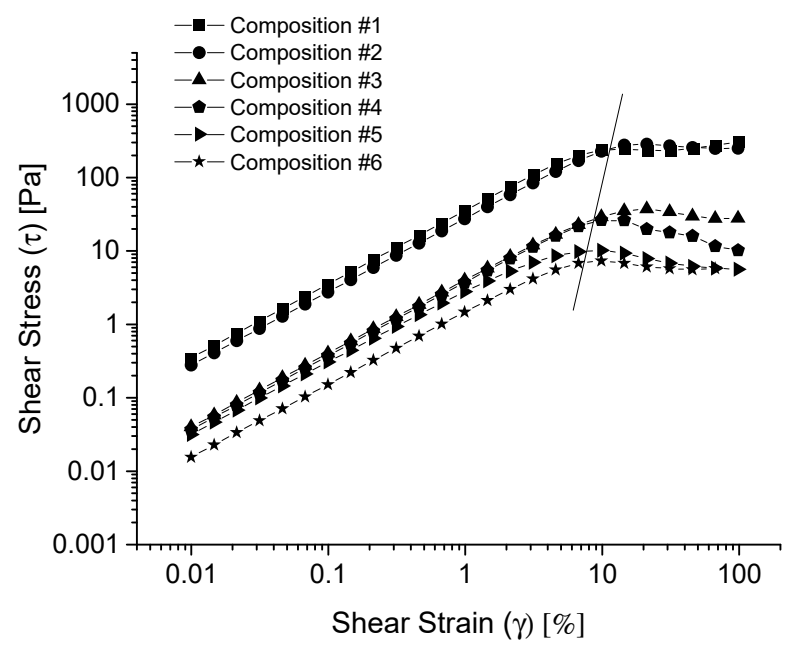

(c)

Figure 2. Shear stress $(\tau)$ versus shear strain $(\gamma)$ curves (in logarithmic scales) for the given co-hydrogel systems prepared in water (a), phosphate-buffered saline (PBS) buffer (b), and glycine/ $\mathrm{NaOH}$ buffer (c). 
The above results can be further elaborated by the experimental data of the storage modulus, $G^{\prime}$, and the loss modulus, $G^{\prime \prime}$, versus the shear strain. $G^{\prime}$ describes the component of the elastic property of the co-hydrogel while $G^{\prime \prime}$ describes that of the viscous property of the co-hydrogel. Figure 3 shows the $G^{\prime}$ and $G^{\prime \prime}$ versus shear strain $(\gamma)$ curves (in logarithmic scales) for the given co-hydrogels prepared in water (a), PBS buffer (b) and glycine/ $\mathrm{NaOH}$ buffer (c). The $G^{\prime}$ and $G^{\prime \prime}$ curves show the constant plateau values with small shear strains for all the samples. This kind of plateau region is referred to as the linear viscoelastic (LVE) region. All the $G^{\prime}$ values are larger than the $G^{\prime \prime}$ values for all the samples in the LVE region indicating the gel structures for all the samples. The law of elasticity for oscillatory shear test, $\mathrm{G}^{*}=\sqrt{\mathrm{G}^{2}+\mathrm{G}^{\prime 2}}=\tau / \gamma$, represents the strength of the gel networks. Therefore, the decreased values of $G^{\prime}$ and $G^{\prime \prime}$ with the increased portion of $R_{f}-P E G-g-P A A$ in each of the figures indicates the weakened cross-linkages of the co-hydrogel networks, which provide additional proof for the incorporation of $R_{f}-P E G-g-P A A$ into the $R_{f}-P E G-R_{f}$ hydrogels. With the increase of shear strain for each of the samples, both the $G^{\prime}$ and $G^{\prime \prime}$ curves have gone through the cross-over point (the flow point) where the magnitude of $G^{\prime}$ and $G^{\prime \prime}$ values changed from $G^{\prime}>G^{\prime \prime}$ to $G^{\prime}<G^{\prime \prime}$. This shows that the co-hydrogel network gradually broke down by the increased shear strain deformation after the flow point.

The influence of $\mathrm{pH}$ in the strength of the co-hydrogel networks can also be observed by comparing the curves of the moduli of the co-hydrogels prepared in water and the different $\mathrm{pH}$ buffers. The moduli are generally larger for the co-hydrogels prepared in the PBS buffer than those prepared in the glycine/ $\mathrm{NaOH}$ buffer. The co-hydrogels prepared in water had the smallest moduli. This order is consistent with the observed shear stresses for the co-hydrogels prepared in water and the buffer solutions. At first glance, it seems that because the charges of the PAA block in $\mathrm{R}_{\mathrm{f}}$-PEG-g-PAA depend on the $\mathrm{pH}$, the $\mathrm{pH}$ affects the hydrogen bonding and electrostatic interactions among the PAA and PEG blocks. In water $(\mathrm{pH}=4-5)$, most of the carboxylic acid groups were neutral. In the PBS buffer $(\mathrm{pH}=7.2)$, part of the carboxylic groups were neutral and part of them were negatively charged. In the glycine/ $\mathrm{NaOH}$ buffer $(\mathrm{pH}=10.6)$, more of the carboxylic acid groups were negatively charged. Therefore, the inter-chain hydrogen bonding and static interactions among the PAA blocks, and between the PAA block and the PEG block would be different at different $\mathrm{pH}$ values, which would in turn affect the strength of the gel networks. However, the general trends of the moduli were the same for the $100 \% R_{f}-P E G-R_{f}$ samples in water and the different buffers where no PAA was involved. Furthermore, the $\mathrm{pH}$ values were almost the same for the $100 \% \mathrm{R}_{\mathrm{f}}-\mathrm{PEG}-\mathrm{R}_{\mathrm{f}}$ hydrogels prepared in water and in the PBS buffer solution, which indicates that the effect might not be caused by different $\mathrm{pH}$ values. Therefore, the ultimate reason can only be the ionic effect of the salts or the conjugate acid-base pairs used to make the buffer solutions. It is known that the $R_{f}$-cores formed by the hydrophobic effect [44]. Thus, the ions in the buffer solutions could make the $\mathrm{R}_{\mathrm{f}}$-groups associate together more strongly, and it was also possible that more $R_{\mathrm{f}}$-groups might form one $\mathrm{R}_{\mathrm{f}}$-core.

\subsubsection{Frequency Sweep}

Figure 4 shows the $G^{\prime}$ and $G^{\prime \prime}$ versus angular frequency, $\omega$, curves (in logarithmic scales) for the given co-hydrogel systems prepared in (a) water, (b) PBS buffer and (c) glycine/ $\mathrm{NaOH}$ buffer. All the samples displayed $\mathrm{G}^{\prime}>\mathrm{G}^{\prime \prime}$ curves in the $0.1-100 \mathrm{rad} / \mathrm{s}$ angular frequency range with the only exceptions for the samples with the highest $\mathrm{R}_{\mathrm{f}}$ PEG-g-PAA portions in the ends of the curves. $G^{\prime}>G^{\prime \prime}$ shows the physically cross-linked co-hydrogel networks in the tested angular frequency range. In addition, the moduli increased with the increase of the angular frequency, which demonstrates the physical dispersion stability of the co-hydrogels. Thus, the co-hydrogel materials can stay in 3D shapes with long-term storage stability. The $\mathrm{G}^{\prime}$ values decreased with the increase of the $\mathrm{R}_{\mathrm{f}}$-PEG-g-PAA component. $\mathrm{G}^{\prime}$ shows the cross-linking density. Therefore, with the increase of the $R_{\mathrm{f}}$-PEG-g-PAA portion, the number of physical cross-linking between the micelles decreased. However, all of the co-hydrogels could stay in 3D shapes with long- 
term dispersion stability. This result also indicates that the $\mathrm{R}_{\mathrm{f}}$-PEG-g-PAA physically incorporated into the $\mathrm{R}_{\mathrm{f}}-\mathrm{PEG}-\mathrm{R}_{\mathrm{f}}$ hydrogel.

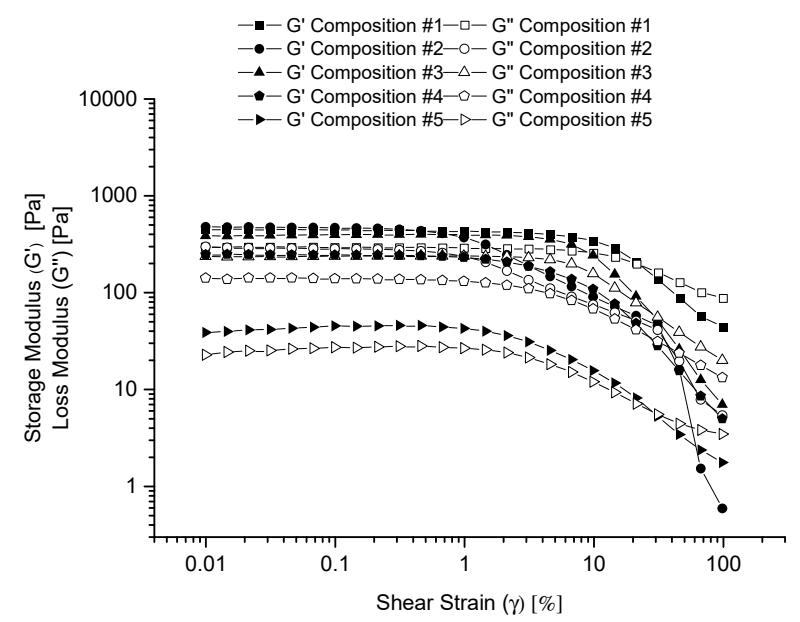

(a)

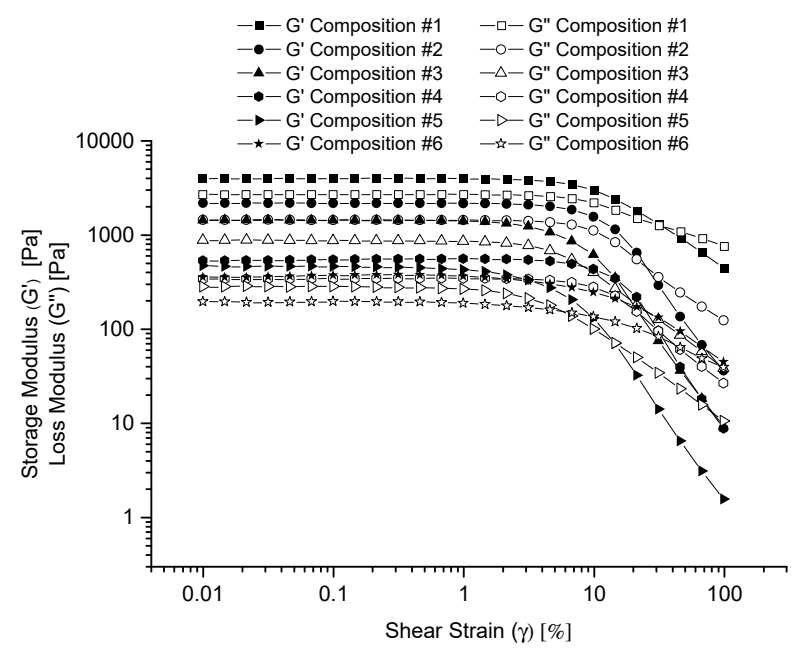

(b)

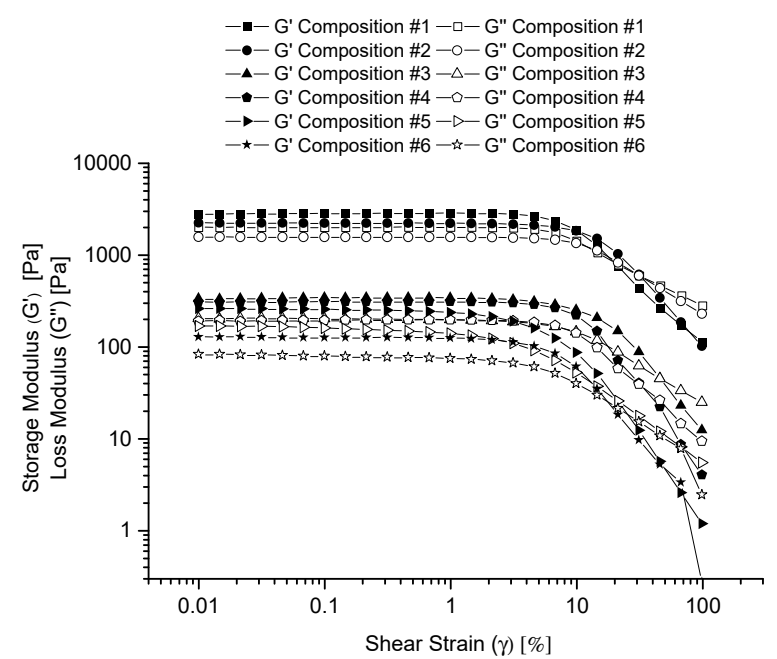

(c)

Figure 3. $G^{\prime}$ and $G^{\prime \prime}$ versus $\gamma$ curves (in logarithmic scales) for the given co-hydrogels prepared in water (a), PBS buffer (b) and glycine/ $\mathrm{NaOH}$ buffer (c). 


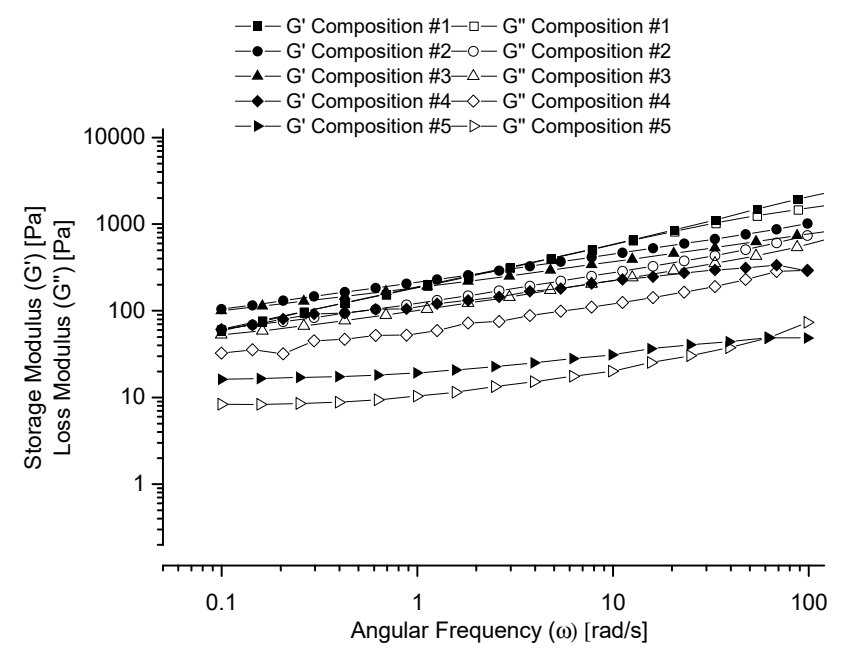

(a)

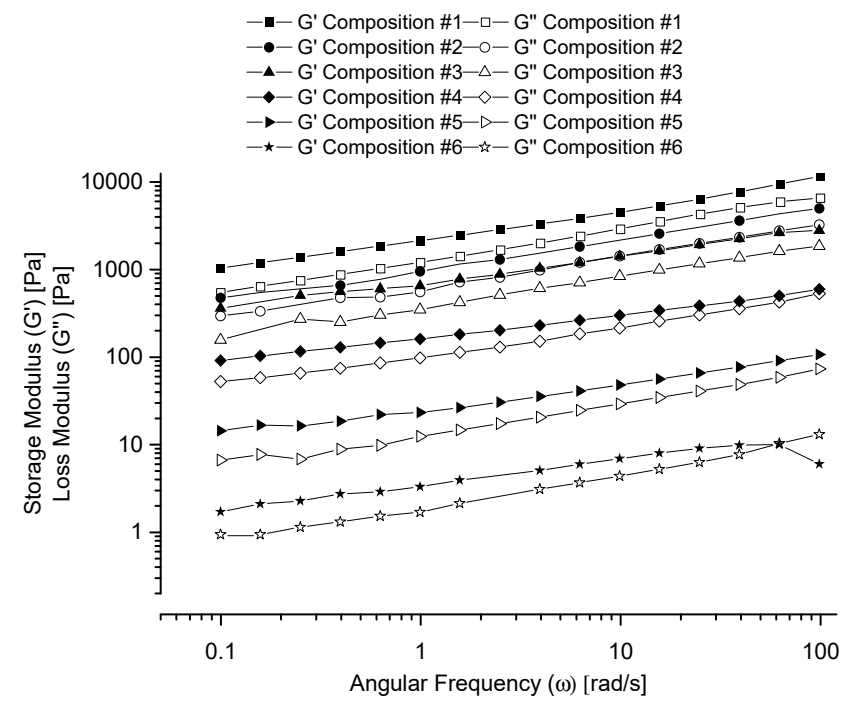

(b)

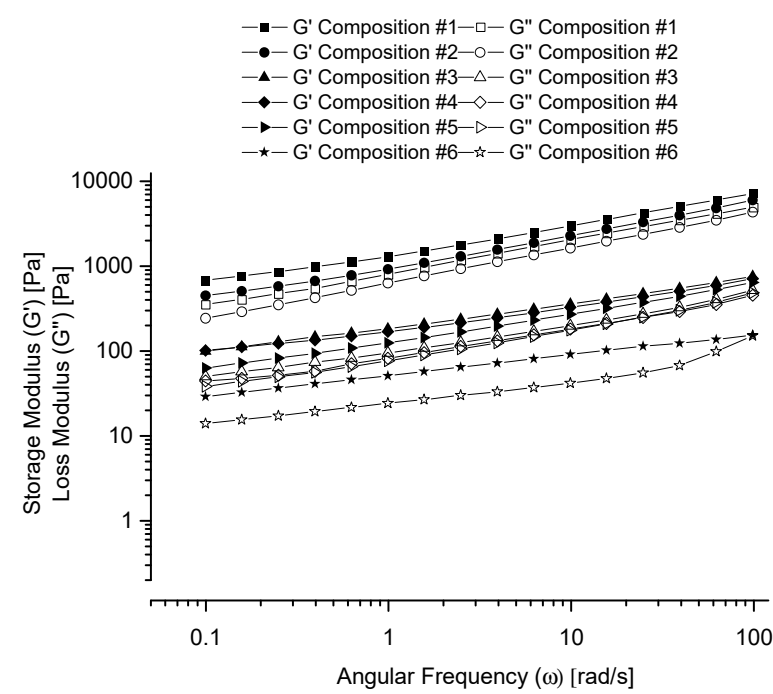

(c)

Figure 4. $G^{\prime}$ and $G^{\prime \prime}$ versus $\omega$ curves (in logarithmic scales) for the given co-hydrogel systems prepared in water (a), PBS buffer (b) and glycine/ $\mathrm{NaOH}$ buffer (c). 
The network of this hydrogel system was self-assembled by individual PEG chains. It is a network at the molecular level, but not one formed by bundles of macromolecules as encountered in many chemically cross-linked hydrogel systems [18]. Therefore, the resolution of the current scanning electron microscopy (SEM) method (in the order of magnitude of $\mu \mathrm{m}$ ) may not reveal the molecular-level structures of the co-hydrogel networks. Ideally, fluorescent labeling method [45] would provide direct evidence for the formation of the co-hydrogel system if fluorophores could be used to label the $R_{f}$-groups of $R_{f}-P E G-R_{f}$ and $\mathrm{R}_{\mathrm{f}}$-PEG-PAA. However, our currently used materials and synthetic methods do not allow the straightforward fluorescent labeling to the $\mathrm{R}_{\mathrm{f}}$-groups. Work in this direction would project a future research of chemistry. This research is to use the tensile test and rheological methods to indirectly address this issue. As discussed above, the experimental results of the tensile test on the control samples, compositions 8 to 10 in Table 1, demonstrate the necessity of the $R_{f}$-group of $R_{f}$-PEG-PAA to associate with the $R_{f}$-cores formed by $R_{f}-P E G-R_{f}$. In addition, results of the rheometric measurements demonstrate the viscoelastic properties of the co-hydrogels with different $R_{f}-P E G-P A A / R_{f}-P E G-R_{f}$ ratios, which in turn verifies the association of the $R_{f}$-group of $R_{f}$-PEG-PAA with the $R_{f}$-cores formed by $R_{f}-P E G-R_{f}$.

\section{Conclusions}

$\mathrm{R}_{\mathrm{f}}$-PEG-g-PAA copolymers were synthesized and integrated into the physically crosslinked $R_{f}-P E G-R_{f}$ micellar network through self-assembly. Results of the tensile strength tests demonstrate that the co-hydrogel system possesses $\mathrm{pH}$-sensitive mucoadhesive properties. The mucoadhesion is stronger at low $\mathrm{pH}(4-5)$ and high $\mathrm{pH}(10.6)$ than in neutral condition, which shows the primary hydrogen bonding interaction and electrostatic interaction between the PAA block and mucin. Experimental results of the control experiments indicate that the $R_{\mathrm{f}}$-group of the $\mathrm{R}_{\mathrm{f}}$-PEG-g-PAA associated with the $\mathrm{R}_{\mathrm{f}}$-cores of the $\mathrm{R}_{\mathrm{f}}$-PEG$\mathrm{R}_{\mathrm{f}}$ micelles, thus holding the PAA block though the PEG chain on the gel surface. Results of the rheological experiments demonstrate that the $\mathrm{R}_{\mathrm{f}}$-PEG-g-PAA self-assembled into the $\mathrm{R}_{\mathrm{f}}-\mathrm{PEG}-\mathrm{R}_{\mathrm{f}}$ hydrogel network. The resulting co-hydrogels at different $\mathrm{pH}$ conditions could stay in physically cross-linked 3D networks with long-term physical dispersion stability although the number of physical cross-linkages between the micelles decreased with the increase of the $R_{f}$-PEG-g-PAA component. Higher ionic strength in the buffer solutions strengthened the physical association of the $\mathrm{R}_{\mathrm{f}}$-cores through the hydrophobic effect, thus firming up the interconnection of the micelles through the co-hydrogel network. Results of our co-hydrogel incubation experiments indicate that the co-hydrogels can stay in equilibrium with the sol phases in the water and the buffer solutions.

Self-assembly of the physically cross-linked hydrogel network of the $R_{f}-P E G-R_{f} / R_{f}-$ PEG-g-PAA system makes it possible to develop an organic solvent-soluble mucoadhesive hydrogel platform in an aqueous environment with tunable factors including mesh size of the hydrogel network, strength of the physically cross-linked micelles, and binding force of the mucoadhesion through modifying the length of the PEG chain, size of the $\mathrm{R}_{\mathrm{f}}$ group, length of PAA polymer, and the repeat unit, $n$, of $\left(R_{f}-P E G\right)_{n}$ - multi-block copolymers for mucosal membrane-localized drug-delivery applications.

Supplementary Materials: The following are available online at https: / www.mdpi.com/article/ 10.3390 /polym13121956/s1: Scheme S1. Route of synthesis of $\mathrm{R}_{\mathrm{f}}-\mathrm{PEG}-\mathrm{R}_{\mathrm{f}}$. Scheme S2. Route of synthesis of $R_{\mathrm{f}}$-PEG-g-PAA. Figure S1. Photo picture of the Texture Analyzer experimental setting. Figure S2. The lower plate shows the sample setting of the pig small intestine on the surface of the platform of the texture analyzer. The upper component shows the TA-10 probe on the surface of which a filter paper soaked with $R_{\mathrm{f}}-\mathrm{PEG}-\mathrm{R}_{\mathrm{f}} / \mathrm{R}_{\mathrm{f}}$-PEG-g-PAA co-hydrogel was glued on. Figure S3. Matrix-assisted laser desorption/ionization-time of flight (MALDI-TOF) mass spectrometry (MS) spectrum of the PEG showing an average molecular weight of $6.2 \times 10^{3}$. Figure S4. MALDI TOF mass spectrum of the $\mathrm{R}_{\mathrm{f}}-\mathrm{PEG}-\mathrm{R}_{\mathrm{f}}$ showing an average molecular weight of $7.4 \times 10^{3}$. Figure S5 MALDI TOF mass spectrum of the $\mathrm{R}_{\mathrm{f}}-\mathrm{PEG}-\mathrm{OH}$ showing an average molecular weight of $6.8 \times 10^{3}$. Figure S6. MALDI TOF mass spectrum of the $\mathrm{R}_{\mathrm{f}}$-PEG-g-PAA showing an average molecular weight of $8.0 \times 10^{3}$. Figure S7. ${ }^{1} \mathrm{H}$ NMR (nuclear magnetic resonance) spectrum of the $\mathrm{R}_{\mathrm{f}}-\mathrm{PEG}-\mathrm{g}-\mathrm{PAA}$. The 
sharp peak at 3.5407 ppm is from the PEG block. Figure S8. Comparison of PAA region of the ${ }^{1} \mathrm{H}$

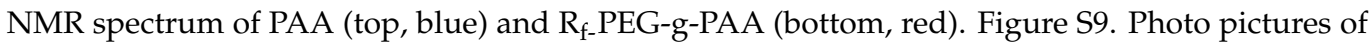
the sol-gel two-phase coexistences of the $5 \% R_{f}$-PEG-g-PAA/95\% $R_{f}-P E G-R_{f}$ (composition \# 2), and the $10 \% \mathrm{R}_{\mathrm{f}}$-PEG-g-PAA $/ 90 \% \mathrm{R}_{\mathrm{f}}$-PEG- $\mathrm{R}_{\mathrm{f}}$ (composition \# 4), respectively, prepared in the following solutions at $37{ }^{\circ} \mathrm{C}$ after 11 days: (A) and (B) in PBS buffer ( $\left.\mathrm{pH}=7.2\right)$; (C) and (d) in DI water $(\mathrm{pH}=4-5)$; and $(\mathrm{E})$ and $(\mathrm{F})$ in the glycine/sodium hydroxide buffer $(\mathrm{pH}=10.6)$. Figure S10. Force $(\mathrm{g})$ vs. time (s) curves for the $5.0 \%$ mucin Type II sample interacting with the $R_{f}-P E G-R_{f} / R_{f}-P E G-g-P A A$ (here the -g- was omitted in the inset) co-hydrogels and the control samples prepared in water. Figure S11. Bar graph representation of the relative MDSs with respect to the MDS of the water sample for the $5.0 \%$ mucin Type II sample interacting with the $R_{\mathrm{f}}-\mathrm{PEG}-\mathrm{R}_{\mathrm{f}} / \mathrm{R}_{\mathrm{f}}-\mathrm{PEG}-\mathrm{g}-\mathrm{PAA}$ co-hydrogels and the control samples prepared in water. Figure S12. Force (g) vs. time (s) curves for the $5.0 \%$ mucin Type II sample interacting with the $\mathrm{R}_{\mathrm{f}}$-PEG- $\mathrm{R}_{\mathrm{f}} / \mathrm{R}_{\mathrm{f}}$-PEG-g-PAA (here the - $\mathrm{g}$ - was omitted in the inset) co-hydrogels prepared in the PBS buffer. Figure S13. Bar graph representation of the relative MDSs with respect to the MDS of the PBS buffer sample for the 5.0\% mucin Type II sample interacting with the $R_{f}-P E G-R_{f} / R_{f}-P E G-g-P A A$ co-hydrogels prepared in the PBS buffer. Figure S14. Force $(g)$ vs. time (s) curves for the $5.0 \%$ mucin Type II sample interacting with the $R_{\mathrm{f}}-\mathrm{PEG}-\mathrm{R}_{\mathrm{f}} / \mathrm{R}_{\mathrm{f}}-\mathrm{PEG}-\mathrm{g}-\mathrm{PAA}$ (here the -g- was omitted in the inset) co-hydrogel prepared in the glycine/ $\mathrm{NaOH}$ buffer. Figure S15. Bar graph representation of the relative MDSs with respect to the MDS of the PBS buffer sample for the $5.0 \%$ mucin Type II sample interacting with the $\mathrm{R}_{\mathrm{f}}-\mathrm{PEG}-\mathrm{R}_{\mathrm{f}} / \mathrm{R}_{\mathrm{f}}-\mathrm{PEG}-\mathrm{g}-\mathrm{PAA}$ co-hydrogel prepared in the glycine/ $\mathrm{NaOH}$ buffer. Figure S16. Force $(\mathrm{g})$ vs. time (s) curves of the interactions of the various $R_{\mathrm{f}}-\mathrm{PEG}-\mathrm{R}_{\mathrm{f}} / \mathrm{R}_{\mathrm{f}}$-PEG-g-PAA co-hydrogels and the control samples prepared in water with the pig small intestine surface. Figure S17. Bar graph presentation showing the relative MDSs of various $R_{\mathrm{f}}-\mathrm{PEG}-\mathrm{R}_{\mathrm{f}} / \mathrm{R}_{\mathrm{f}}$-PEG-g-PAA co-hydrogels and the control samples prepared in water with the pig small intestine surface. Figure S18. Force (g) vs. time (s) curves of the interactions of the various $\mathrm{R}_{\mathrm{f}}$-PEG- $\mathrm{R}_{\mathrm{f}} / \mathrm{R}_{\mathrm{f}}$-PEG-g-PAA co-hydrogels and the control sample prepared in PBS buffer with the pig small intestine surface. Figure S19. Bar graph presentation showing the relative MDSs of various $\mathrm{R}_{\mathrm{f}}$-PEG- $\mathrm{R}_{\mathrm{f}} / \mathrm{R}_{\mathrm{f}}$-PEG-g-PAA co-hydrogels and the control samples prepared in the PBS buffer with the pig small intestine surface. Figure S20. Force vs. time curves of the interactions of various $\mathrm{R}_{\mathrm{f}}-\mathrm{PEG}-\mathrm{R}_{\mathrm{f}} / \mathrm{R}_{\mathrm{f}}$-PEG-g-PAA co-hydrogels and the control sample prepared in the glycine/ $\mathrm{NaOH}$ buffer with the pig small intestine surface. Figure S21. Bar graph presentation showing the relative MDSs for various $R_{\mathrm{f}}-\mathrm{PEG}-\mathrm{R}_{\mathrm{f}} / \mathrm{R}_{\mathrm{f}}$-PEG-g-PAA co-hydrogels and the control samples prepared in glycine $/ \mathrm{NaOH}$ buffer interacting with the pig small intestine surface.

Author Contributions: Conceptualization, Y.B.; methodology, Y.B., Y.S. and A.F.P.; software, Y.S., A.F.P. and Y.B.; validation, Y.S., A.F.P., I.L.C., N.B.-R. and Y.B.; formal analysis, Y.S., A.F.P. and Y.B.; investigation, Y.S., A.F.P., I.L.C., N.B.-R. and Y.B.; resources, Y.B.; data curation, Y.S., A.F.P., I.L.C., N.B.-R. and Y.B.; writing-original draft preparation, Y.S., A.F.P. and Y.B.; writing-review and editing, Y.S., I.L.C., N.B.-R. and Y.B.; visualization, Y.S., A.F.P. and Y.B.; supervision, Y.B.; project administration, Y.B.; funding acquisition, Y.B. All authors have read and agreed to the published version of the manuscript.

Funding: This research was funded by a CSULA mini-grant, and the NSF awards DMR-1727015 and 1919722; A.P. thanks the support of NIGMS and NIH through the LABB-PhD award (Grant number 5R25GM054939).

Institutional Review Board Statement: Ethical review and approval were not applicable because the porcine stomach mucin Type II was provided by Sigma-Aldrich, USA, and the pig small intestine was provided by BioreclamationIVT, USA.

Data Availability Statement: Data is contained within the article and supplementary material. The data presented in this study are available in [Mucoadhesive and Rheological Studies on the CoHydrogel Systems of Poly(Ethylene Glycol) Copolymers with Fluoroalkyl and Poly(Acrylic Acid), and the corresponding Supplementary Materials].

Conflicts of Interest: The authors declare no conflict of interest. 


\section{References}

1. Peppas, N.A.; Little, M.D.; Huang, Y. Bioadhesive controlled release systems. In Handbook of Pharmaceutical Controlled Release Technology; Wise, D.L., Brannon-Peppas, L., Klibanov, A.M., Langer, R.L., Mikos, A.G., Peppas, N.A., Trantolo, D.J., Wnek, G.E., Yaszemski, M.J., Eds.; Dekker: New York, NY, USA, 2000; pp. 255-269.

2. Robinson, J.R.; Lee, J.W.; Park, J.H. Bioadhesive-based dosage forms: The next generation. J. Pharm. Sci. 2000, 89, 850-866.

3. Peppas, N.A.; Bures, P.; Leobandung, W.; Ichikawa, H. Hydrogels in pharmaceutical formulations. Eur J. Pharm. Biopharm. 2000, 50, 27-46. [CrossRef]

4. Harris, J.M. Ploy(ethylene glycol) Chemistry. Biotechnical and Biomedical Applications; Plenum Press: New York, NY, USA, 1992.

5. Zalipsky, S. Functionalized Poly(ethylene glycol) for Preparation of Biologically Relevant Conjugates. Bioconjugate Chem. 1995, 6, 150-165. [CrossRef]

6. $\quad$ Marshall, D.; Pedley, R.B.; Boden, J.A.; Boden, R.; Melton, R.G.; Begent, R.H. Polyethylene glycol modification of a galactosylated streptavidin clearing agent: Effects on immunogenicity and clearance of a biotinylated anti-tumour antibody. Br. J. Cancer 1996, 73, 565-572. [CrossRef]

7. Harris, J.M.; Chess, R.B. Effect of pegylation on pharmaceuticals. Nat. Rev. Drug Discov. 2003, 2, 214-221. [CrossRef]

8. Hirai, Y.; Terashima, T.; Takenaka, M.; Sawamoto, M. Precision Self-Assembly of Amphiphilic Random Copolymers into Uniform and Self-Sorting Nanocompartments in Water. Macromolecules 2016, 49, 5084-5091. [CrossRef]

9. Park, H.; Robinson, J.R. Physico-chemical properties of water insoluble polymers important to mucin/epithelial adhesion. J. Control Release 1985, 2, 47-57. [CrossRef]

10. Park, H.; Robinson, J.R. Mechanisms of mucoadhesion of poly(acrylic acid) hydrogels. Pharm. Res. 1987, 4, 457-464. [CrossRef] [PubMed]

11. Ch'ng, H.S.; Park, H.; Kelly, P.; Robinson, J.R. Bioadhesive polymers as platforms for oral controlled drug delivery. II. Synthesis and evaluation of some swelling, water-insoluble bioadhesive polymers. J. Pharm. Sci. 1985, 74, 399-405. [CrossRef]

12. Singla, A.K.; Chawla, M.; Singh, A. Potential applications of carbomer in oral mucoadhesive controlled drug delivery system: A review. Drug Dev. Ind. Pharm. 2000, 26, 913-924. [CrossRef] [PubMed]

13. Ahuja, A.; Khar, R.K.; Ali, J. Mucoadhesive drug delivery systems. Drug Dev. Ind. Pharm. 1997, 23, 489-515. [CrossRef]

14. Serra, L.; Doménech, J.; Peppas, N.A. Design of poly(ethylene glycol)-tethered copolymers as novel mucoadhesive drug delivery systems. Eur. J. Pharm. Biopharm. 2006, 63, 11-18. [CrossRef]

15. Montaser, A.S.; Rehan, M.; El-Naggar, M.E. pH-Thermosensitive hydrogel based on polyvinyl alcohol/sodium alginate/Nisopropyl acrylamide composite for treating re-infected wounds. Int. J. Biol. Macromol. 2019, 124, 1016-1024. [CrossRef]

16. Structure and Function of Gastrointestinal Mucus, 1st ed.; Allen, A., Ed.; Raven Press: New York, NY, USA, 1981 ; pp. 617-639.

17. Taylor, C.; Allen, A.; Dettmar, P.; Pearson, J. The gel matrix of gastric mucus is maintained by a complex interplay of transient and nontransient associations. Biomacromolecules 2003, 4, 922-927. [CrossRef] [PubMed]

18. Sharaf, S.; El-Naggar, M.E. Wound dressing properties of cationized cotton fabric treated with carrageenan/cyclodextrin hydrogel loaded with honey bee propolis extract. Int. J. Biol. Macromol. 2019, 133, 583-591. [CrossRef] [PubMed]

19. Jiang, Z.; Liu, H.; He, H.; Ribbe, A.E.; Thayumanavan, S. Blended Assemblies of Amphiphilic Random and Block Copolymers for Tunable Encapsulation and Release of Hydrophobic Guest Molecules. Macromolecules 2020, 53, 2713-2723. [CrossRef]

20. Satarkar, N.S.; Biswala, D.; Hilta, J.Z. Hydrogel nanocomposites: A review of applications as remote controlled biomaterials. Soft Matter 2021, 6, 2364-2371. [CrossRef]

21. Das, N. Preparation methods and properties of hydrogel: A review. Int. J. Pharm. Pharm. Sci. 2013, 5, $112-117$.

22. Akhtar, M.F.; Hanif, M.; Ranjha, N.M. Methods of synthesis of hydrogels ... A review. Saudi Pharm. J. 2016, 24, 554-559. [CrossRef] [PubMed]

23. Tae, G.; Kornfield, J.A.; Hubbell, J.A.; Johannsmann, D.; Hogen-Esch, T.E. Hydrogels with Controlled, Surface Erosion Characteristics from Self-Assembly of Fluoroalkyl-Ended Poly(ethylene glycol). Macromolecules 2001, 34, 6409-6419. [CrossRef]

24. Tae, G.; Kornfield, J.A.; Hubbell, J.A.; Lal, J. Ordering Transitions of Fluoroalkyl-Ended Poly(ethylene glycol): Rheology and SANS. Macromolecules 2002, 35, 4448-4457. [CrossRef]

25. Taea, G.; Kornfielda, J.A.; Hubbell, J.A. Sustained release of human growth hormone from in situ forming hydrogels using self-assembly of fluoroalkyl-ended poly(ethylene glycol). Biomaterials 2005, 26, 5259-5266. [CrossRef] [PubMed]

26. Peppas, N.A.; Buri, P.A. Surface, interfacial and molecular aspects of polymer bioadhesion on soft tissues. J. Control Release 1985, 2, 257-275. [CrossRef]

27. Kammer, H.W. Adhesion between polymers. Acta Polym. 1983, 34, 112-118. [CrossRef]

28. Ponchel, G.; Touchard, F.; Wouessidjewe, D.; Duchene, D.; Peppas, N.A. Bioadhesive analysis of controlled release systems. I. Fracture and interpenetration analysis in poly(acrylic acid)-containing systems. J. Control Release 1987, 5, 129-141. [CrossRef]

29. Bulcke, A.I.V.D.; Bogdanov, B.; Rooze, N.D.; Schacht, E.H.; Cornelissen, M.; Berghmans, H. Structural and Rheological Properties of Methacrylamide Modified Gelatin Hydrogels. Biomacromolecules 2000, 1, 31-38. [CrossRef]

30. Moura, M.J.; Figueiredo, M.M.; Gil, M.H. Rheological Study of Genipin Cross-Linked Chitosan Hydrogels. Biomacromolecules 2007, 8, 3823-3829. [CrossRef]

31. Krop, E.M.; Hetherington, M.M.; Holmes, M.; Miquel, S.; Sarkar, A. On relating rheology and oral tribology to sensory properties in hydrogels. Food Hydrocoll. 2019, 88, 101-113. [CrossRef] 
32. Derkach, S.R.; Ilyin, S.O.; Maklakova, A.A.; Kulichikhin, V.G.; Malkin, A.Y. The rheology of gelatin hydrogels modified by k-carrageenan. LWT-Food Sci. Technol. 2015, 63, 612-619. [CrossRef]

33. Lapasin, R.; Abrami, M.; Grassi, M.; Šebenik, U. Rheology of Laponite-scleroglucan hydrogels. Carbohydr. Polym. 2017, 168, 290-300. [CrossRef] [PubMed]

34. Krishnan, A.S.; Seifert, S.; Lee, B.; Khana, S.A.; Spontak, R.J. Cosolvent-regulated time-composition rheological equivalence in block copolymer solutions. Soft Matter 2010, 6, 4331-4334. [CrossRef]

35. Di Xu, D.B.; Gersappe, D.; Sokolov, J.C.; Rafailovich, M.H.; Lombardi, J. Rheology of Poly(N-isopropylacrylamide)-Clay Nanocomposite Hydrogels. Macromolecules 2015, 48, 840-846.

36. Liu, X.; Mao, Y.; Mathias, E.V.; Ma, C.; Franco, O.; Ba, Y.; Kornfield, J.A.; Wang, T.; Xue, L.; Zhou, B.; et al. Study the property of double-ended fluoroalkyl poly(ethylene glycol) hydrogel as a depot for hydrophobic drug delivery using electron paramagnetic resonance technique and cell proliferation assay. J. Sol-Gel. Sci. Techn. 2008, 45, 269-278. [CrossRef]

37. Mathias, E.V.; Liu, X.; Franco, O.; Khan, I.; Ba, Y.; Kornfield, J.A. A Model of Drug-Loaded Fluorocarbon-based Micelles Studied by Electron-Spin Induced 19F Relaxation NMR and Molecular Dynamics Modeling. Langmuir 2008, 24, 692-700. [CrossRef]

38. Mathias, E.V.; Aponte, J.; Ba, Y.; Kornfield, J. Properties of Small Molecular Drug Loading and Diffusion in a Fluorinated PEG Hydrogel Studied by 1H Diffuion NMR and 19F Spin Diffusion NMR. Colloid Polym. Sci. 2010, 288, 1655-1663. [CrossRef] [PubMed]

39. Xu, B.; Li, L.; Yekta, A.; Masoumi, Z.; Kanagalingam, S.; Winnik, M.A.; Zhang, K.; Macdonald, P.M.; Menchen, S. Synthesis, Characterization, and Rheological Behavior of Polyethylene Glycols End-Capped with Fluorocarbon Hydrophobes. Langmuir 1997, 13, 2447-2456. [CrossRef]

40. Hillenkamp, F.; Karas, M.; Beavis, R.C.; Chait, B.T. Matrix-assisted laser desorption/ionization mass spectrometry of biopolymers. Anal. Chem. 1991, 63, 1193A-1203A. [CrossRef]

41. Li, Y.; Hoskins, J.N.; Sreerama, S.G.; Grayson, S.M. MALDI-TOF Mass Spectral Characterization of Polymers Containing an Azide Group: Evidence of Metastable Ions. Macromolecules 2010, 43, 6225-6228. [CrossRef]

42. Ivarsson, D.; Wahlgren, M. Comparison of in vitro methods of measuring mucoadhesion: Ellipsometry, tensile strength and rheological measurements. Colloids Surf. B Biointerfaces 2012, 92, 353-359. [CrossRef]

43. Bromberg, L.; Temchenko, M.; Alakhov, V.; Hatton, T.A. Bioadhesive properties and rheology of polyether-modified poly(acrylic acid) hydrogels. Int. J. Pharm. 2004, 282, 45-60. [CrossRef]

44. Chandler, D. Interfaces and the driving force of hydrophobic assembly. Nature 2005, 437, 640-647. [CrossRef] [PubMed]

45. Toseland, C.P. Fluorescent labeling and modification of proteins. J. Chem. Biol. 2013, 6, 85-95. [CrossRef] [PubMed] 